\title{
Risk, Entrepreneurship and Human Capital Accumulation
}

\author{
Murat F. Iyigun \\ iyigunm@frb.gov \\ Ann L. Owen \\ aowen@frb.gov
}

Board of Governors of the Federal Reserve System

\begin{abstract}
We examine the implications for growth and development of the existence of two types of human capital: entrepreneurial and professional. While entrepreneurial human capital plays a relatively more important role in intermediate income countries, professional human capital is relatively more abundant in richer economies. Because the return to entrepreneurial ventures is risky, individuals devote less time to the accumulation of entrepreneurial human capital and more to the accumulation of professional human capital as per capita income grows, thus changing the relative stocks of these skills. We also show that those countries that initially have too little of either entrepreneurial or professional human capital may end up in a development trap. Finally, because the social marginal returns to education and experience may differ from the private marginal returns, the steady state can be characterized by either too much or too little education.
\end{abstract}

Keywords: Human Capital, Occupational Choice, Education, Entrepreneurship, Growth JEL Classification Numbers: J24, O11, O40

John M. Heitkemper provided valuable research assistance. This paper represents the views of the authors and should not be interpreted as reflecting those of the Board of Governors of the Federal Reserve System or other members of its staff. Please send all correspondence to: The Board of Governors of the Federal Reserve System, Mail Stop 23, Washington, D.C. 20551. 


\section{Introduction}

Both entrepreneurs and professionals are important components of an economy's human capital stock. But each provide different skills to the economy and influence the level of technology and the utilization of the existing technology in potentially different ways. This paper explores the implications for growth of the existence of more than one type of human capital, showing how the choice between entrepreneurship and professional employment evolves as an economy develops and examining how individuals' decisions to accumulate different types of human capital affect the economy's long-run potential.

There are three main results. First, entrepreneurial human capital plays a relatively more important role in intermediate income countries, whereas professional human capital is relatively more abundant in richer economies. We demonstrate that as an economy develops, individuals choose to invest more time accumulating professional skills through schooling than accumulating entrepreneurial human capital. The resulting change in the relative stocks of entrepreneurial and professional human capital is a direct consequence of our assumption that providing professional services is a relatively safe activity and providing entrepreneurial skills is risky. As per capita income grows and the payoff to being a professional increases, individuals are less willing to gamble on entrepreneurial ventures. This phenomenon occurs even though the expected value of entrepreneurship rises with per capita income. While entrepreneurs in a more developed economy face a clearly better lottery than entrepreneurs in a less developed economy, the price of the lottery ticket-foregone professional earnings-is higher in the developed economy, making individuals less willing to take the bet.

Second, we find that, in an economy where both entrepreneurial and professional human capital affect the future level of technology, the initial stocks of both types of human capital are important for the process of development. If a country starts off with too little of either entrepreneurial or professional human capital, it may end up in a 
development trap in which production is carried out only with unskilled labor and there is no human capital investment of any type.

Our third result is the natural outcome of considering more than one type of human capital in the presence of a production externality-an inefficient allocation of time between schooling and experience can result. By identifying alternative means of accumulating human capital, we are able to show that an economy in the early stages of development may have too little education, but in later stages of development may have too much education. Whether there is too much education or too little, however, depends on how professional and entrepreneurial skills affect the level of technology. When entrepreneurial human capital is more important than professional human capital in determining the level of technology, the steady state will have too many professionals and too few entrepreneurs. Thus, a reduction in education and an increase in entrepreneurial experience could increase per capita income. Appropriate tax policy may be able to achieve the efficient outcome.

This paper is motivated, in part, by a stylized fact-in economies with higher per capita income, fewer individuals are employers compared to the number of individuals who work for others (see Figure 1). If we equate working for another with less risk, our model would generate such an outcome, with individuals choosing the relatively safe return of schooling in greater proportion as per capita income grows.

We are also motivated by previous work that has examined how occupational choice is affected by development. Banerjee and Newman (1993) show how the distribution of wealth and credit market imperfections influence an individual's ability to become an entrepreneur. In their model, there is a fixed cost to becoming an entrepreneur and the distribution of wealth determines the percent of the population that undertakes such a venture and becomes an employer. We take a slightly different view on defining entrepreneurship, choosing to focus on the element of risk inherent in the concept rather 
than the structure of employment. Thus, while both models generate the result that high income economies will have more employer-employee relationships, our model focuses particularly on how the incentives to accumulate professional and entrepreneurial human capital change as an economy grows. Specifically, while Banerjee and Newman (1993) demonstrate that economic development may foster entrepreneurial investment, our model shows that, as economies develop, the increasing risk of entreprenuerial ventures has an offsetting negative effect on resources devoted to entrepreneurship relative to that devoted to professional activities.

Our use of more than one type of human capital also ties into recent work that has begun to question the role education plays in development and growth. Benhabib and Spiegel (1994) argue that educated labor is not a factor of production but only affects per capita income through its effect on the level of technology. Fershtman, Murphy and Weiss (1996) investigate conditions under which nonmonetary rewards in the form of occupational status lead to inefficiencies in investment in education and a lower growth rate. Pritchett (1995) goes further in challenging the role education plays in determining per capita income, empirically finding a negative association between the growth of education and total factor productivity. By acknowledging the validity of more than one type of human capital, our paper points out that alternatives to schooling can also play an important role in development, implicitly downplaying the importance of education.

The groundwork for our model has been laid in many previous papers on related topics. One of the main tenets of this paper is that the skills individuals accumulate through work experience are an important part of human capital. Support for this idea can be found in microeconomic studies of wage determinants [see for example Becker (1993) and Mincer $(1993,1996)]$, and also in macroeconomic examinations of growth through a learning-by-doing process [e.g. Lucas(1993) and Stokey (1988)]. A second element of our model is the role that the existing level of human capital plays in the 
determination of future technology, a theme that has been emphasized in the growth literature [see Lucas (1988), Azariadis and Drazen (1990), Romer (1990) and Galor and Tsiddon (1997) to name a few]. However, our definition of human capital that includes entrepreneurial human capital accumulated through work experience enriches the usual story and allows us to examine the role that education plays in determining the growth and level of per capita income with a slightly different perspective. Thus, in our model, the level of human capital effectively employed in an economy depends on the total skills of the workforce and not just those accumulated by investing in formal education.

In what follows, we present a three-period overlapping-generations model. Human capital and a labor aggregate are the only factors of production, but human capital is the sum of both professional and entrepreneurial human capital. When the wages paid to human capital providers are greater than the wages earned by labor, individuals accumulate professional human capital by investing time in schooling and accumulate entrepreneurial human capital by investing time working as an entrepreneur. A key difference between the two types of human capital is that the reward paid to professional human capital is certain but the payoff to entrepreneurial human capital is not.

The level of technology employed by any one generation of workers is determined by the level of professional and entrepreneurial human capital of the previous generation. Thus, as the stock of professional and entrepreneurial skills grow, the compensation to professional human capital and the expected compensation to entrepreneurial human capital increase. However, as the return to the safe activity increases, individuals devote more time to schooling and less time to gaining entrepreneurial experience. In essence, individuals in high income economies with higher wages to professionals have more to lose by gambling on an entrepreneurial venture.

If the way professional and entrepreneurial human capital are combined in output production is different from the way the two types of human capital are combined to 
determine the level of technology, then time devoted to schooling will be inefficient. In other words, if developing the technology utilizes the two types of human capital in a different way than implementing the technology, individuals, whose compensation is based on their contribution to output production, will not choose the socially optimal combination of schooling and entrepreneurial investment. In particular, if entrepreneurial ventures are more important in determining the level of technology and less important in its utilization, then the steady state level of education will be too high and per capita income would be higher with more entrepreneurs and fewer professionals.

These results are developed in the following four sections: Section 2 describes the basic model, Section 3 discusses its dynamic behavior, Section 4 considers social externalities, and Section 5 concludes.

\section{The Model}

\subsection{Production}

Consider an economy that operates in a perfectly competitive world in which economic activity extends over an infinite discrete time. The output of the economy, $Y_{t}$, is a single homogeneous good produced by a CRS production function that uses a labor aggregate, $L_{t}$, and human capital, $H_{t}$, as inputs. The total output produced at time t, $Y_{t}$, is given by

$$
Y_{t}=\lambda_{t} H_{t}+L_{t}
$$

where the technology level in period $t$, denoted by $\lambda_{t}$, complements the human capital input, $H_{t}$. Thus, technological change in this economy is skill-biased.

We assume that markets are competitive which implies that factor inputs earn 
their marginal products:

$$
w_{t}^{h}=\lambda_{t} \quad \text { and } \quad w_{t}^{l}=1
$$

where $w_{t}^{h}$ and $w_{t}^{l}$ respectively denote the returns to human capital and labor.

\subsection{Individuals}

Individuals live for three periods in overlapping generations. The size of the population is normalized to one and there is no population growth. Individuals are endowed with one unit of time in every period. At birth, they are endowed with an innate mental ability level, $a_{i}$, which we assume to be drawn from a uniform distribution function. Therefore,

$$
\int_{\underline{a}}^{\bar{a}} \frac{1}{\bar{a}-\underline{a}} d a_{i}=1
$$

where $\bar{a}, \underline{a}$ respectively denote the upper and lower bounds of the ability distribution.

Individuals' innate mental ability levels, $a_{i}$, augment their human capital input. In the first period, individuals decide whether they will be labor or human capital suppliers during their lifetime. If they chose to become labor providers, they devote all of their time endowment in the first and second periods to work. If they choose to become human capital suppliers, they also decide on what fraction of their time in the first period to devote to accumulating professional human capital through education and to acquiring entrepreneurial human capital by working in an entrepreneurial venture ${ }^{1}$. In the second period, individuals supply their total human capital endowment and they save. In the third period, individuals consume their savings.

\footnotetext{
${ }^{1}$ We have chosen this specification to keep the analysis tractable. A more realistic version of the model, however, could incorporate another dimension into innate mental ability. In that case, those individuals who possess higher innate entreprenuerial ability (relative to professional) would specialize in entrepreneurship while others would choose to become professionals. The qualitative nature of the conclusions we reach below should not be affected under this alternative formulation.
} 
We assume that the time devoted to education, $s_{t}^{i}$, increases an individual's stock of professional human capital, $p_{t+1}^{i}$, whereas time devoted to work, $x_{t}^{i}$, increases his entrepreneurial human capital, $e_{t+1}^{i}$ :

$$
e_{t+1}^{i}=a_{i} f\left(x_{t}^{i}\right),
$$

and,

$$
p_{t+1}^{i}=a_{i} f\left(s_{t}^{i}\right)
$$

where the standard Inada conditions hold and where $\forall x_{t}^{i}, s_{t}^{i} \geq 0, f^{\prime}()>0,. f^{\prime \prime}()<$.0 . One can think of the time devoted to work to augment entrepreneurial human capital as a start-up cost for entrepreneurial ventures. During this time the individual can learn effective techniques for running a business.

We also assume that there is uncertainty in the return to entrepreneurial ventures but that the return to education (which generates professional human capital in the following period) is not subject to any uncertainty. Specifically, individual $i$ 's income from becoming an entrepreneur, $\left(I_{t+1}^{i}\right)^{e}$, is

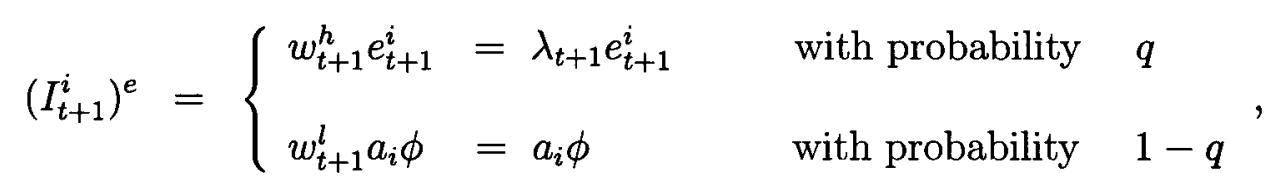

and his income from professional activities, $\left(I_{t+1}^{i}\right)^{p}$, is

$$
\left(I_{t+1}^{i}\right)^{p}=w_{t+1}^{h} p_{t+1}^{i}=\lambda_{t+1} p_{t+1}^{i} .
$$

where $0<q \leq 1$. In equation (6), $\phi$ represents the fixed payoff to being an entrepreneur in the bad state. The probabilities $q$ and $1-q$ are the probabilities of success and failure 
faced by each individual. In aggregate, given a sufficiently large number of entrepreneurs, $q$ percent will succeed and $1-q$ percent will fail. Those that fail essentially supply $a_{i} \phi$ units of unskilled labor to the economy.

Finally, we assume that the level of technology in period $t+1, \lambda_{t+1}$, is determined by the average levels of the entrepreneurial and professional human capital in the previous period. Specifically,

$$
\lambda_{t+1}=\lambda\left(e_{t}, p_{t}\right)
$$

where $\lambda_{t+1}^{e} \equiv \frac{\partial \lambda_{t+1}}{\partial e_{t}}, \lambda_{t+1}^{p} \equiv \frac{\partial \lambda_{t+1}}{\partial p_{t}}>0, \lambda_{t+1}^{e e} \equiv \frac{\partial^{2} \lambda_{t+1}}{\partial e_{t}^{2}}, \lambda_{t+1}^{p p} \equiv \frac{\partial^{2} \lambda_{t+1}}{\partial p_{t}^{2}}<0$ and $\lambda_{t+1}^{e p} \equiv \frac{\partial^{2} \lambda_{t+1}}{\partial e_{t} \partial p_{t}}$ $\lambda_{t+1}^{p e} \equiv \frac{\partial^{2} \lambda_{t+1}}{\partial p_{t} \partial e_{t}}>0$.

Individuals maximize expected utility from consumption in the third period and their rate of time preference is zero. We assume that the expected utility of individual $i$ of generation $t$ takes the following form ${ }^{2}$ :

$$
E\left[u\left(c_{t+2}^{i}\right) \mid t\right]=q \ln \left[\left(c_{t+2}^{i}\right)^{q}\right]+(1-q) \ln \left[\left(c_{t+2}^{i}\right)^{1-q}\right]
$$

where $\left(c_{t+2}^{i}\right)^{q}$ and $\left(c_{t+2}^{i}\right)^{1-q}$ respectively denote the consumption of individual $i$ in the good and bad states.

In addition to $s_{t}^{i}+x_{t}^{i} \leq 1$, individual $i$ is subject to the budget constraint below:

$$
I_{t+1}^{i}= \begin{cases}2 & \text { if } i \text { is a labor provider } \\ \left(I_{t+1}^{i}\right)^{e}+\left(I_{t+1}^{i}\right)^{p} & \text { if } i \text { is a human capital provider }\end{cases}
$$

\footnotetext{
${ }^{2}$ We have chosen logarithmic preferences to demonstrate that increasing relative risk aversion is not necessary to generate the declining willingness to gamble on entrepreneurship as per capita income grows. Clearly, this result could be generated with any utility function that features increasing relative risk aversion, and some, but not all, utility functions that feature decreasing relative risk aversion.
} 
where $\left(I_{t+1}^{i}\right)^{e}$ and $\left(I_{t+1}^{i}\right)^{p}$ are given by equations (6) and (7).

Given the problem specified above, there exists a threshold innate ability level for every period $t$-that, henceforth we will denote $\tilde{a}_{t}$-below which individual $i$ will choose to be a labor supplier. Combining equations (4)-(7), (9) and (10), we can show that $\tilde{a}_{t}$ satisfies the following equality:

$$
q \ln \left\{\lambda_{t+1} \tilde{a}_{t}\left[f\left(s_{t}^{i}\right)+f\left(1-s_{t}^{i}\right)\right]\right\}+(1-q) \ln \left\{\tilde{a}_{t}\left[\phi+\lambda_{t+1} f\left(s_{t}^{i}\right)\right]\right\}=\ln (2)
$$

If individual $i^{\prime}$ s innate mental ability level is such that $a_{i}>\tilde{a}_{t}$, individual $i$-while young-chooses to accumulate human capital instead of supplying labor. In that case, the optimal amount of time allocated to education by the individual, $s_{t}^{i}$, satisfies

$$
\frac{q}{1-q}=-\frac{\lambda_{t+1}\left[f\left(s_{t}^{i}\right)+f\left(1-s_{t}^{i}\right)\right]}{\phi+\lambda_{t+1} f\left(s_{t}^{i}\right)} \frac{f^{\prime}\left(s_{t}^{i}\right)}{f^{\prime}\left(s_{t}^{i}\right)-f^{\prime}\left(1-s_{t}^{i}\right)}
$$

Note that the first-order condition above implies that the amount of time individual $i$ devotes to schooling is independent of his innate ability level $a_{i}$. Put differently, $s_{t}^{i}=s_{t}$ $\forall i$ such that $a_{i}>\tilde{a}_{t}^{3}$.

Equations (11) and (12) lead to the propositions below:

Proposition 1: $\forall t \geq 0$ such that $\tilde{a}_{t}<\bar{a}$, the threshold innate ability level in period $t$, $\tilde{a}_{t}$, is a decreasing function of average levels of entrepreneurial and professional human capital in the same period, $e_{t}$ and $p_{t}$. Namely,

\footnotetext{
${ }^{3}$ An alternative modelling choice, having the payoff to entrepreneurship in the bad state not depend on individual ability, would have resulted in individuals of different ability choosing different levels of schooling. We did not pursue this alternative model in the subsequent analysis because of its intractability.
} 


$$
\frac{\partial \tilde{a}_{t}}{\partial e_{t}}, \quad \frac{\partial \tilde{a}_{t}}{\partial p_{t}} \quad<0 .
$$

Proof: Using equation (11) and the implicit function theorem it is straightforward to show

$$
\frac{\partial \tilde{a}_{t}}{\partial e_{t}}=-\frac{\tilde{a}_{t} \lambda_{t+1}^{e}}{\lambda_{t+1}}<0,
$$

and,

$$
\frac{\partial \tilde{a}_{t}}{\partial p_{t}}=-\frac{\tilde{a}_{t} \lambda_{t+1}^{p}}{\lambda_{t+1}}<0 .
$$

The above proposition shows that, in the early stages of development when the returns to both types of human capital input are relatively small, only those with the highest ability levels choose to supply human capital, whereas a majority of the population chooses to supply labor. As improvements in technology raise the relative return to human capital, however, a larger fraction of the population chooses to accumulate human capital while young by allocating time to education and working as entrepreneurs ${ }^{4}$.

Proposition 2: (i) $\forall q, 0<q \leq 1$, and $\forall t \geq 0$ such that $\tilde{a}_{t}<\bar{a}$, the optimal amount of time individual $i$ chooses to devote to education, $s_{t}$, is such that $s_{t} \geq \frac{1}{2}$. (ii) $\forall q$,

\footnotetext{
${ }^{4}$ In our model, human capital accumulation is rationed by ability. It would be straightforward to adapt our model to other rationing rules such as one that takes into account parental wealth and ability such as that found in Owen and Weil (forthcoming).
} 
$0<q<1$, and $\forall t \geq 0$ such that $\tilde{a}_{t}<\bar{a}$, the amount of time individual $i$ chooses to devote to education in period $t, s_{t}$, is an increasing function of average levels of entrepreneurial and professional human capital in the same period, $e_{t}$ and $p_{t}$. Namely,

$$
\frac{\partial s_{t}}{\partial e_{t}}, \quad \frac{\partial s_{t}}{\partial p_{t}} \quad>0
$$

Proof: (i) Given that the lhs and the first term on the rhs of equation (12) are positive, we establish that the term $\frac{f^{\prime}\left(s_{t}\right)}{f^{\prime}\left(s_{t}\right)-f^{\prime}\left(1-s_{t}\right)}$ on the rhs needs to be non-positive. Thus, $f^{\prime}\left(s_{t}\right)-f^{\prime}\left(1-s_{t}\right) \leq 0 \Leftrightarrow s_{t} \geq \frac{1}{2} \forall i$ such that $a_{i}>\tilde{a}_{t}$.

(ii) Using the first-order condition given by (12) and invoking-once again-the implicit function theorem, we get

$$
\frac{\partial s_{t}}{\partial e_{t}}=-\frac{1}{\eta} \frac{\phi \lambda_{t+1}^{e} f^{\prime}\left(s_{t}\right)}{\phi+\lambda_{t+1} f\left(s_{t}\right)}>0
$$

where

$$
\eta=\left\{\begin{array}{cc}
\lambda_{t+1} f^{\prime}\left(s_{t}\right) \frac{\phi\left[f^{\prime}\left(s_{t}\right)-f^{\prime}\left(1-s_{t}\right)\right]-\lambda_{t+1}\left[f\left(s_{t}\right) f^{\prime}\left(1-s_{t}\right)+f\left(1-s_{t}\right) f^{\prime}\left(s_{t}\right)\right]}{\phi+\lambda_{t+1} f\left(s_{t}\right)} & \\
- & <0 . \\
\lambda_{t+1}\left[f\left(s_{t}\right)+f\left(1-s_{t}\right)\right] \frac{f^{\prime \prime}\left(s_{t}\right) f^{\prime}\left(1-s_{t}\right)+f^{\prime \prime}\left(1-s_{t}\right) f^{\prime}\left(s_{t}\right)}{f^{\prime}\left(s_{t}\right)-f^{\prime}\left(1-s_{t}\right)} &
\end{array}\right.
$$

$\frac{\partial s_{t}}{\partial p_{t}}$ is equal to an expression almost identical to (17), where $\lambda_{t+1}^{e}$ is replaced by $\lambda_{t+1}^{p}$.

Proposition 2 shows how increases in the human capital stock, which raise the level of technology and per capita income, affect the accumulation of the two different types 
of human capital. Specifically, it demonstrates that technological change, by inducing human capital suppliers to devote more time to schooling, leads to a shift away from entrepreneurial human capital accumulation. The reason is that technological change not only raises the relative return to human capital, but it also increases the risk of time invested in entreprenuerial human capital accumulation in the sense that the discrepancy between the payoffs in the good and bad states increases as the economy develops. As a result, those individuals who find it optimal to become human capital suppliers choose to stay in school longer and develop a higher ratio of professional to entrepreneurial skills. As will be seen in the next section, the change in the ratio of professional to entrepreneurial skills does not necessarily imply a reduction in aggregate entrepreneurial skills, because the aggregate value is also affected by decreases in $\tilde{a}_{t}$ which cause more individuals to become human capital providers.

\section{The Evolution of the Economy}

Given (11) and the specification of the technology parameter, $\lambda_{t+1}$, in (8), we identify that there exists a minimum level of technology below which all individuals choose to work as raw labor and noone allocates time to activities that foster human capital accumulation. Let

$\mu=\left\{\left(e_{t}, p_{t}\right) \mid q \ln \left\{\lambda_{t+1} \bar{a}\left[f\left(s_{t}\right)+f\left(1-s_{t}\right)\right]\right\}+(1-q) \ln \left\{\bar{a}\left[\phi+\lambda_{t+1} f\left(s_{t}\right)\right]\right\} \leq \ln (2)\right\}$

Thus, when $\left(e_{t}, p_{t}\right) \in \mu, \bar{a} \leq \tilde{a}_{t}$, not even the highest ability individuals choose to devote time to education or work experience and $e_{t+1}=p_{t+1}=0$. 
In contrast, for all pairs of entrepreneurial and professional human capital in any given period $t\left(e_{t}, p_{t}\right) \notin \mu$, the dynamical system is characterized by the two equations that govern the evolution of entrepreneurial and professional human capital stocks. Namely,

$$
e_{t+1}= \begin{cases}\int_{\tilde{a}_{t}}^{\bar{a}} \frac{1}{\overline{\bar{a}}-\underline{a}} f\left(x_{t}^{i}\right) d a_{i}=\frac{\bar{a}-\tilde{a}_{t}}{\bar{a}-\underline{a}} f\left(x_{t}\right)=\frac{\bar{a}-\tilde{a}_{t}}{\bar{a}-\underline{a}} f\left(1-s_{t}\right) & \text { when } \bar{a}>\tilde{a}_{t}>\underline{a} \\ f\left(1-s_{t}\right) & \text { when } \tilde{a}_{t} \leq \underline{a}\end{cases}
$$

$$
p_{t+1}=\left\{\begin{array}{ll}
\int_{\tilde{a}_{t}}^{\bar{a}} \frac{1}{\bar{a}-\underline{a}} f\left(s_{t}^{i}\right) d a_{i}=\frac{\bar{a}-\tilde{a}_{t}}{\bar{a}-\underline{a}} f\left(s_{t}\right) & \text { when } \bar{a}>\tilde{a}_{t}>\underline{a} \\
f\left(s_{t}\right) & \text { when } \tilde{a}_{t} \leq \underline{a}
\end{array} .\right.
$$

Given that both $\tilde{a}_{t}$ and $s_{t}$ are functions of the technology level in period $t+1, \lambda_{t+1}$, which in turn is a function of the entrepreneurial and professional human capital in the previous period, $e_{t}$ and $p_{t}$,

$$
e_{t+1}=\Gamma\left(e_{t}, p_{t}\right) \quad \text { and } \quad p_{t+1}=\Psi\left(e_{t}, p_{t}\right)
$$

In this economy, a steady-state is characterized by $(\bar{e}, \bar{p})$ such that, $\forall t \geq T, \bar{e}=\Gamma(\bar{e}$, $\bar{p})$ and $\bar{p}=\Psi(\bar{e}, \bar{p})$.

Proposition 3: $\forall q, \tilde{q} \leq q \leq 1$ and $\left(e_{0}, p_{0}\right) \notin \mu, \exists$ a non-trivial, stable, steady-state equilibrium for the dynamical system specified in (20) if

(i) the technology of human capital production, $f($.$) , is sufficiently productive,$ (ii) $\phi$ is sufficiently small. 
Proof: See Appendix for the derivation of the dynamical system depicted in Figure 2.

[Figure 2 about here.]

The reason for the first condition is intuitive-the technology of human capital production must be effective enough to induce individuals to accumulate entrepreneurial and professional skills. The reason for the second condition is not as intuitive but, as can be seen in the details of the proof, when $\phi$ is too large, the substitution effect of individuals reallocating time away from entrepreneurship always dominates the effect of a decrease in $\tilde{a}_{t}$, which increases the fraction of human capital providers. This makes it more difficult to establish the existence of a non-trivial steady state.

There are several important implications of the dynamics of our model. First, entreprenerial human capital plays a relatively (but not absolutely) more important role in intermediate income countries, whereas professional human capital is relatively (and absolutely) more abundant in richer economies. For those countries that start off with a sufficiently high combination of entrepreneurial and professional human capital, an increasing fraction of the population chooses to invest in both types of human capital during the transition to the steady state. Moreover, those who choose to do so devote an increasing amount of time to the accumulation of professional human capital and a decreasing amount of time to entrepreneurial human capital. The reason, as we have 
stated earlier, is that as per capita income grows and the payoff to being a professional increases, individuals are less willing to gamble on entrepreneurial ventures. Of course, higher probabilities of entrepreneurial success (higher values of $q$ ) generate higher stocks of entrepreneurial skills.

Second, the initial stock of both entrepreneurial and professional human capital are important for the process of development. Notably, those countries that start off with too little entrepreneurial or professional human capital end up in a development trap in which production is carried out with raw labor input only and there is no human capital investment of any type. This result obtains because both entrepreneurial and professional human capital play a role in the determination of the level of technology. Therefore, when either type of human capital is relatively small initially, the level of technology and the return to human capital investment relative to raw labor input are also small. As a result, an increasing fraction of individuals choose to become raw labor suppliers instead of becoming human capital providers.

A relevant example of the importance of this second point may be found in the former east-bloc countries. As some have pointed out [e.g. Fan, Overland and Spagat (1996)], these economies have a highly educated labor force and may be primed for an economic take-off. However, our model highlights the possibility that these economies, if short on entrepreneurs, may be further away from the high-income steady state than education levels alone would indicate. In fact, some of them may even be unable to reach it.

\section{Externalities}

A third implication of our model is that because the social marginal returns to work and education may differ from the private marginal returns, it is likely that even 
the steady state with positive human capital investment is inefficient. However, because in our model the alternative to education is also a productive activity, the source of the inefficiency is not standard-there may be too much investment in education in the steady state. Specifically, when entrepreneurs are more important in determining the level of technology than professionals, the high-income steady state may be characterized by over-investment in education. Similarly, when professional human capital has greater influence on the technology in use, the high-income steady state has too little education. The key feature of the model that produces these unique inefficiencies is that entrepreneurial and professional human capital may be combined in different ways in production and in the formation of the technology of production.

A market economy may be able to achieve a more efficient mix of professional and entrepreneurial skills through tax policy which alters their relative private returns. Although in our model the cost of becoming either type of human capital provider is simply an opportunity cost, one can imagine a richer model in which out-of-pocket expenses are also necessary. In such a model, tuition tax credits may encourage more investment in education and generate more professionals while reduced capital gains taxes may be able to increase the relative attractiveness of entrepreneurship ${ }^{5}$. Thus, depending on the nature of the inefficiency, appropriate tax policy may be able to increase steady state income.

It is important to note that the inefficiency results not from too much human capital, but from a misallocation of the existing human capital stock between professional and entrepreneurial activities. In fact, a more efficient ratio of professional and entrepreneurial skills will raise the steady state level of technology and increase the wages paid to human capital providers and the economy's human capital stock.

\footnotetext{
${ }^{5}$ Of course, given exogenous government spending, the tax breaks given to one type of worker will need to be recouped through other taxes. These "additional" taxes must be collected in a non-distortionary manner, i.e. a lump-sum tax, in order to ensure that this policy is effective.
} 


\section{Conclusion}

The model we present above demonstrates why both entrepreneurs and professionals are important for development. It shows that the private incentives to accumulate entrepreneurial relative to professional skills are greater in intermediate income countries and that-due to the inherent riskiness of entrepreneurial ventures-those incentives decline relative to the incentives to become a professional as countries grow richer. Nonetheless, the initial stock of both types of human capital matter, because together they determine the return to human capital relative to raw labor. Thus, the

initial conditions are important in determining whether countries converge to an equilibrium in which, for a larger fraction of the population, investing time in human capital accumulation will be more profitable relative to labor provision.

Our model also demonstrates that when more than one type of human capital exists, individuals may not allocate their time efficiently to the accumulation of these different skills. More generally, our results indicate that a thorough macroeconomic investigation of all of the channels of human capital accumulation is necessary to effectively formulate and implement the most successful policies. This is a fruitful area for further research. 


\section{References}

Azariadis, C. and A. Drazen, 1990, "Threshold Externalities in Economic Development," Quarterly Journal of Economics, 105, 501-26.

Banerjee, A. and A. Newman, 1993, "Occupational Choice and the Process of Economic Development," Journal of Political Economy, 101, 2, 274-98.

Becker, G. S., 1993, Human Capital: A Theoretical and Empirical Analysis, with Special Reference to Education, (The University of Chicago Press, Chicago).

Benhabib, J. and M. M. Spiegel, 1994, "The Role of Human Capital in Economic Development: Evidence from aggregate cross-country Data," Journal of Monetary Economics, $34,143-173$.

Fan C. S., J. Overland and M. Spagat, 1996, "Human Capital and Russia's Economic Transformation," Transition, Vol. 2, No: 13.

Fershtman, C., K.M. Murphy, and Y. Weiss, 1996, "Social Status, Education and Growth," Journal of Political Economy, 104(1), February, 108-132.

Galor, O. and D. Tsiddon, 1997, "The Distribution of Human Capital and Economic Growth," Journal of Economic Growth, 2, 96-124.

Lucas, R. E., 1993, "Making a Miracle," Econometrica, Vol. 61, No:2, March, 251-72.

Mincer, J., 1993, Studies in Human Capital: Collected Essays of Jacob Mincer, Vol. 1, (Brookfield, VT: Edward Elgar Publishing Company).

Mincer, J., 1996, "Economic Development, Growth of Human Capital and the Dynamics of the Wage Structure," Journal of Economic Growth, 1(1), March, 29-48.

Owen A. L. and D. N. Weil, "Intergenerational Earnings Mobility, Inequality and Growth," Journal of Monetary Economics, forthcoming.

Pritchett, L., 1995, "Where has all the education gone?", mimeo.

Romer, P. M., 1990, "Endogenous Technological Change," Journal of Political Economy, 98(5), October, 571-602. 
Stokey, N. L., 1988, "Learning by Doing and the Introduction of New Goods," Journal of Political Economy, XCVI, 701-717. 


\section{Appendix:}

Proof of Proposition 3:

We prove this proposition in three steps:

- Step 1: We assume that the $E E$ and $P P$ loci do not lie within $\mu$ (i.e. $\tilde{a}_{t}<\bar{a}$ $\forall t$ and equation (19) holds) and demonstrate that they have the form shown in Figure 2.

- Step 2: We then show that, when $q=1$, the $E E$ and $P P$ loci intersect when $f\left(\frac{1}{2}\right)$ is large enough. We relax the assumption that the entire $E E$ and $P P$ loci derived in step 1 lie outside of $\mu$, but show that the intersection of the two loci is still outside of $\mu$.

- Step 3: Finally, we show that decreases in $q$ shift the $E E$ and $P P$ loci continuously, guaranteeing that the $E E$ and $P P$ loci intersect for $\forall q, \tilde{q} \leq q \leq 1$.

\section{Step 1:}

Let

$$
E E=\left\{\left(e_{t}, p_{t}\right) \mid e_{t+1}-e_{t}=\triangle e=0\right\}
$$

and,

$$
P P=\left\{\left(e_{t}, p_{t}\right) \mid p_{t+1}-p_{t}=\triangle p=0\right\}
$$

Assume that $\tilde{a}_{t}<\bar{a} \forall t$. Then, using the implicit function theorem, we are able to show that

$$
\left.\frac{\partial p_{t}}{\partial e_{t}}\right|_{E E}=-\frac{\Gamma_{e}-1}{\Gamma_{p}}=-\frac{\left(\frac{\bar{a}-\tilde{a}_{t}}{\bar{a}-\underline{a}}\right) f^{\prime}\left(1-s_{t}\right) \frac{\partial s_{t}}{\partial e_{t}}+\left(\frac{1}{\bar{a}-\underline{a}}\right) f\left(1-s_{t}\right) \frac{\partial \tilde{a}_{t}}{\partial e_{t}}+1}{\left(\frac{1}{\bar{a}-\underline{a}}\right) f\left(1-s_{t}\right) \frac{\partial \tilde{a}_{t}}{\partial p_{t}}+\left(\frac{\bar{a}-\tilde{a}_{t}}{\bar{a}-\underline{a}}\right) f^{\prime}\left(1-s_{t}\right) \frac{\partial s_{t}}{\partial p_{t}}}
$$

where $\Gamma_{e}$ and $\Gamma_{p}$ respectively denote $\frac{\partial \Gamma}{\partial e_{t}}$ and $\frac{\partial \Gamma}{\partial p_{t}}$. Similarly,

$$
\left.\frac{\partial p_{t}}{\partial e_{t}}\right|_{P P}=-\frac{\Psi_{e}}{\Psi_{p}-1}=-\frac{\left(\frac{\bar{a}-\tilde{a}_{t}}{\bar{a}-\underline{a}}\right) f^{\prime}\left(s_{t}\right) \frac{\partial s_{t}}{\partial e_{t}}-\left(\frac{1}{\bar{a}-\underline{a}}\right) f\left(s_{t}\right) \frac{\partial \tilde{a}_{t}}{\partial e_{t}}}{\left(\frac{\bar{a}-\tilde{a}_{t}}{\bar{a}-\underline{a}}\right) f^{\prime}\left(s_{t}\right) \frac{\partial s_{t}}{\partial p_{t}}-\left(\frac{1}{\bar{a}-\underline{a}}\right) f\left(s_{t}\right) \frac{\partial \tilde{a}_{t}}{\partial p_{t}}-1}
$$


where $\Psi_{e}$ and $\Psi_{p}$ respectively denote $\frac{\partial \Psi}{\partial e_{t}}$ and $\frac{\partial \Psi}{\partial p_{t}}$. By combining (14) and (17) with (A.3), we find that if $\phi$ is relatively small then $\frac{\partial s_{t}}{\partial e_{t}}$ and $\frac{\partial s_{t}}{\partial p_{t}}$ are also small and $\Gamma_{e}, \Gamma_{p} \geq 0 \forall\left(e_{t}\right.$, $\left.p_{t}\right) \notin \mu$. Thus,

$$
\left.\frac{\partial p_{t}}{\partial e_{t}}\right|_{E E}\left\{\begin{array}{lll}
\leq 0 & \text { when } & \Gamma_{e} \geq 1 \\
>0 & \text { when } & \Gamma_{e}<1
\end{array},\right.
$$

and, since $\Psi_{e}, \Psi_{p} \geq 0 \forall\left(e_{t}, p_{t}\right) \notin \mu$, for all parameter specifications,

$$
\left.\frac{\partial p_{t}}{\partial e_{t}}\right|_{P P}\left\{\begin{array}{lll}
\leq 0 & \text { when } & \Psi_{p} \geq 1 \\
>0 & \text { when } & \Psi_{p}<1
\end{array} .\right.
$$

Let $e^{*}$ and $p^{*}$ respectively denote (for given values of $p_{t}$ and $e_{t}$ ) the values of $e_{t}$ and $p_{t}$ that set $q \ln \left\{\lambda_{t+1} \bar{a}\left[f\left(s_{t}\right)+f\left(1-s_{t}\right)\right]\right\}+(1-q) \ln \left\{\bar{a}\left[\phi+\lambda_{t+1} f\left(s_{t}\right)\right]\right\}=\ln (2)$. Given that $\tilde{a}_{t}<\bar{a}, \frac{\partial^{2} \tilde{a}_{t}}{\partial e_{t}^{2}}, \frac{\partial^{2} \tilde{a}_{t}}{\partial p_{t}^{2}}$ are positive, and $\frac{\partial^{2} s t}{\partial e_{t}^{2}}, \frac{\partial^{2} s_{t}}{\partial p_{t}^{2}}$ are negative-as can be verified from (14), (15) and (17)-we determine that

$$
\lim _{e_{t} \rightarrow e^{*}}\left(\frac{\partial p_{t}}{\partial e_{t}} \mid E E\right)<0 \quad \text { and } \quad \lim _{e_{t} \rightarrow \infty}\left(\frac{\partial p_{t}}{\partial e_{t}} \mid E E\right)>0
$$

and, that

$$
\lim _{p_{t} \rightarrow p^{*}}\left(\frac{\partial p_{t}}{\partial e_{t}} \mid P P\right)<0 \quad \text { and } \quad \lim _{p_{t} \rightarrow \infty}\left(\frac{\partial p_{t}}{\partial e_{t}} \mid P P\right)>0
$$

Moreover, given that $s_{t}$ and $\tilde{a}_{t}$ are continuous in $e_{t}$ and $p_{t}$-as implied by Propositions 1 and 2, along the $E E$ locus $\exists\left(e^{\prime}, p^{\prime}\right) \notin \mu$ such that

$$
\left.\frac{\partial p_{t}}{\partial e_{t}}\right|_{E E}=0
$$

and that, along the $P P$ locus $\exists\left(e^{\prime \prime}, p^{\prime \prime}\right) \notin \mu$ such that

$$
\left.\frac{\partial p_{t}}{\partial e_{t}}\right|_{P P}=0
$$

Thus, we establish the general forms of the $E E$ and $P P$ loci on the $(e, p)$ map as shown in Figure 2. 


\section{Step 2:}

Next, we need to demonstrate that, for a non-trivial, stable steady-state to exist, $\exists(\bar{e}, \bar{p}) \notin \mu$.

First consider the case in which $q=1$. When $q=1, s_{t}=\frac{1}{2}$ and $f\left(s_{t}\right)=f\left(1-s_{t}\right)=$ $f\left(\frac{1}{2}\right) \equiv \tilde{f} \forall t$. Moreover, $\frac{\partial s_{t}}{\partial e_{t}}=\frac{\partial s_{t}}{\partial p_{t}}=0$. Thus, (19) simplifies to

$$
e_{t+1}=p_{t+1}= \begin{cases}\tilde{f} \int_{\tilde{a}_{t}}^{\bar{a}} \frac{1}{\bar{a}-\underline{a}} d a_{i}=\frac{\bar{a}-\tilde{a}_{t}}{\bar{a}-\underline{a}} \tilde{f} & \text { when } \tilde{a}_{t}>\underline{a} \\ \tilde{f} & \text { when } \tilde{a}_{t} \leq \underline{a}\end{cases}
$$

Under this case, if a non-trivial steady state equilibrium $(\bar{e}, \bar{p}) \notin \mu$ exists, it satisfies $\bar{e}=\bar{p}$. It also follows directly from (A.11) that if $\exists(\hat{e}, \hat{p}) \in E E$ such that $\hat{e}=\hat{p}$ and $\exists$ $(\tilde{e}, \tilde{p}) \in P P$ such that $\tilde{e}=\tilde{p}$, then $\hat{e}=\tilde{e}=\bar{e}$ and $\hat{p}=\tilde{p}=\bar{p}$ (i.e. if the $E E$ and $P P$ loci cross the $45^{0}$ line, they must cross at the same place.).

Suppose that, there does not exist $(\bar{e}, \bar{p}) \notin \mu$. This implies that $\forall e_{t}=p_{t},\left(e_{t}\right.$, $\left.p_{t}\right) \notin \mu, \triangle p$ and $\triangle e$ are both negative. However, (A.11) indicates that, for a large enough value of $\tilde{f}, \exists\left(e_{t}, p_{t}\right) \notin \mu$ s.t. $e_{t}=p_{t}$ and $\Delta p$ and $\triangle e$ are both positive. Thus, we can ensure that $\exists\left(e_{t}, p_{t}\right) \notin \mu$ s.t. $e_{t}=p_{t}$ and $\triangle p=\triangle e=0$.

\section{Step 3:}

We now show that as $q$ is reduced, $\exists(\bar{e}, \bar{p}) \notin \mu$. First note that, when $q=1$,

$$
\left.\frac{\partial p_{t}}{\partial e_{t}}\right|_{E E} \neq\left.\frac{\partial p_{t}}{\partial e_{t}}\right|_{P P}
$$

when evaluated at $(\bar{e}, \bar{p})$. Thus, we can rule out a tangency at $(\bar{e}, \bar{p})$ when $q=1$.

Using (19), (A.1) and (A.2) and the fact that $s_{t}$ and $\tilde{a}_{t}$ are continuous in $q$, we can also establish that the $E E$ and the $P P$ locus shift continuously in response to changes in $q$. Taken together with the fact that $E E$ and $P P$ are not tangent at $(\bar{e}, \bar{p})$ when $q=1$, we conclude that $\exists q, \tilde{q} \leq q<1$, such that $(\bar{e}, \bar{p}) \notin \mu$ (with $\bar{e}<\bar{p}$ ) exists.

Remark: Note that increases in the effectiveness of education and experience in human capital accumulation-as given by the function $f($.$) -shift E E$ and $P P$ in the opposite direction as decreases in $q$. Thus, the more effective $f($.$) is in converting education$ and experience into human capital, the lower is $\tilde{q}$. 


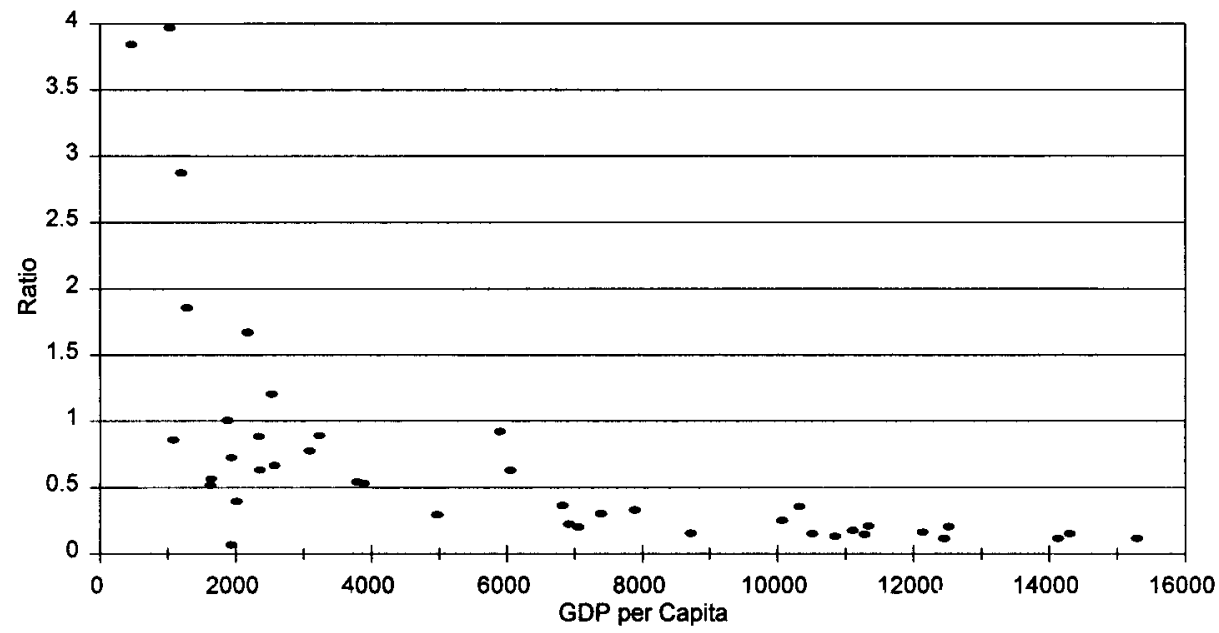

Figure 1:

GDP per capita and the employers to employees ratio ${ }^{6}$. (1980-Sample of 42 countries)

Data Source: World Development Indicators: The World Bank, 1997.

\footnotetext{
${ }^{6}$ Employers include those that are self-employed.
} 


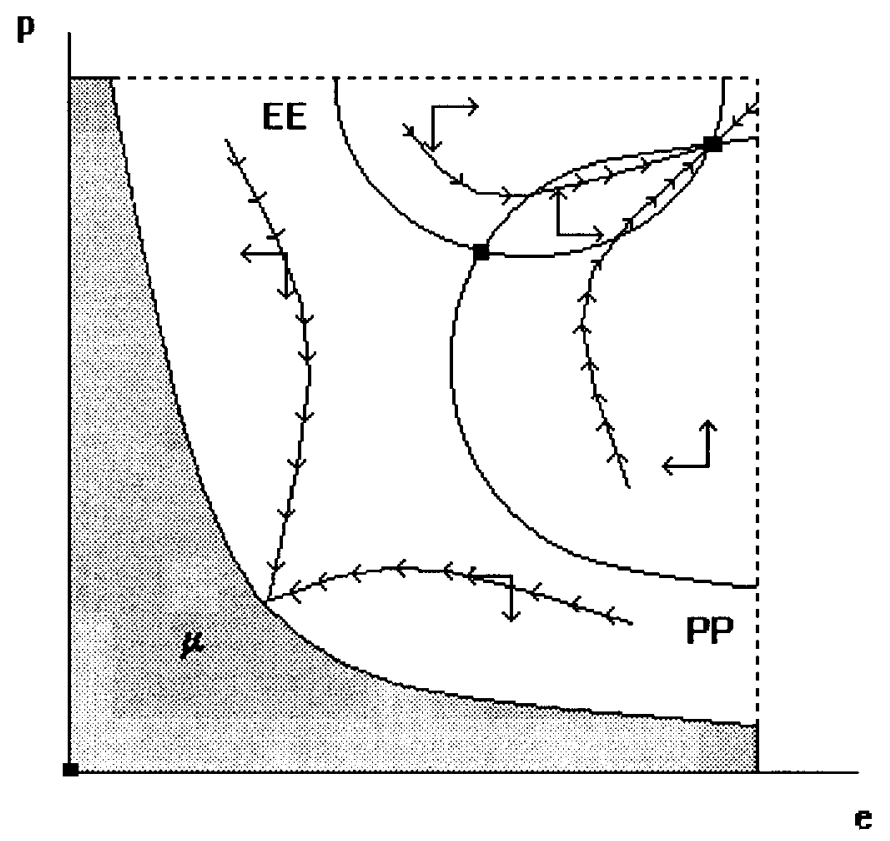

Figure 2:

Entrepreneurial and professional human capital accumulation dynamics. 